\title{
DER ROMANTISCHE PROTAGONIST ALS TRÄGER DES KATHOLISCHEN WELTBILDES. ÜBER DEN IV. TEIL DES DRAMATISCHEN FRAGMENTS DZIADY VON ADAM MICKIEWICZ IN DEUTSCHSPRACHIGEN ÜBERSETZUNGEN
}

\section{Vorbemerkung}

\subsection{Die Komposition und das Weltbild von Dziady als Interpretationsprobleme. Teil IV als erster Höhepunkt der polnischen Romantik}

Die einzigartige Stellung von Mickiewiczs dramatischem Fragment ${ }^{1}$ Dziady in der polnischen Literaturgeschichte ist am treffendsten von Stanisław Pigoń erfasst worden, der das Werk als eine Art Mikrokosmos der polnischen Romantik bezeichnet. Der Entstehungsprozess des Fragments der sogenannten Wilnaer Dziady (Teile II und IV, in Wilna und Kowno entstanden und 1823 herausgegeben) bis zu den Dresdener Dziady (Teil III, 1832 unter dem Eindruck des gescheiterten Novemberaufstands niedergeschrieben) verläuft analog zur Entwicklung der polnischen Romantik: von der Volkstümlichkeit und dem Phantastischen, über die empfindsame „Poesie des verwundeten Herzens“ bis zum polnischen Kampf um die Unabhängigkeit, der in nationalem Märtyrertum und in dem berühmten Konzept Polens als Christus der Völker gipfelt. ${ }^{2}$

Mit der Bemerkung von Pigoń wird die fragmentarische Komposition als eines der grundsätzlichen Interpretationsprobleme im Zusammenhang mit Mickiewiczs

\footnotetext{
${ }^{1}$ Während polnische Literaturhistoriker von Dziady konsequent als von einem romantischen Drama sprechen, sind in der einschlägigen Sekundärliteratur im deutschsprachigen Raum verschiedene Gattungsbezeichnungen anzutreffen: (szenische) Dichtung, Bühnendichtung, Zyklus (R. Fieguth), Drama (B. Schultze), Poem (W. Schamschula). Sie sind alle legitim, aber der Begriff dramatisches Fragment scheint dem im vorliegenden Aufsatz angesprochenen fragmentarischen Charakter des Werkes am besten zu entsprechen.

${ }^{2}$ Vgl. Stanisław Pigoń: Do źródeł Dziadów kowieńsko-wileńskich. In: Ders.: Studia literackie. Kraków 1951. S. 96 f.
} 
Dziady angeschnitten. Die Bühnendichtung zerfällt genau genommen in zwei grundverschiedene Dramen, die wir hier der Einfachheit halber als „GustavDichtung“ und „Konrad-Dichtung“ bezeichnen. ${ }^{3}$ Thematisch sowie im Hinblick auf die Struktur der poetischen Welt unterscheiden sich die einzelnen Dramenteile wesentlich voneinander. ${ }^{4}$ Teil II thematisiert den christlich-heidnischen Volksbrauch der Totenbeschwörung am Allerheiligentag und vertritt die frühe Etappe der polnischen Romantik, die Mickiewicz vorwiegend als Inspiration durch die volkstümliche Dichtung verstand. ${ }^{5}$ Teil IV schildert die tragische Liebesgeschichte Gustavs des Hauptprotagonisten, und ist in mancher Hinsicht der Empfindsamkeit verpflichtet. Als Bindeglied zwischen den Teilen II und IV fungiert das Motiv eines Selbstmörders aus unglücklicher Liebe, der einmal im Jahr als Wiedergänger seinem Grab entsteigt. In Teil III schließlich verwandelt sich der „polnische Werther“ in den stellvertretend für das ganze polnische Volk leidenden, als poeta vates und Retter der Nation auserwählten Konrad.

Die bis heute nicht hinreichend erschlossene Komposition der Dziady rührt nicht nur von der uneinheitlichen Thematik her, sondern auch von der lückenhaften bzw. widersprüchlichen Handlung, von der (aus der Sicht eines traditionellen Lesers) inkonsequent konstruierten, mehrdeutigen Figur des Hauptprotagonisten und nicht zuletzt von der ,unlogischen“ Nummerierung der Teile II, IV, III, die selbst für den Verfasser eine Zeit lang ein Problem darstellte. ${ }^{6}$

Kurz vor der Veröffentlichung der Wilnaer Teile II und IV war sich Mickiewicz der „mangelhaften“ Komposition seines Dramenfragments bewusst und betrachtete sie als eine nachträglich zu korrigierende Übergangsgestalt. Seine immanente Poetik war 1823 viel romantischer als diejenige, zu welcher er sich ausdrücklich bekannte, und sein ästhetisches Bewusstsein blieb hinter der dichterischen Praxis zurück. ${ }^{7}$ Neun Jahre später aber, mit der Niederschrift von Teil III, entschied sich

\footnotetext{
${ }^{3}$ Bezeichnung des Übersetzers Siegfried Lipiners. - Die „Gustav-Dichtung” besteht aus den frühen Teilen von Dziady: II und IV, der vorangestellten Ballade Upiór und dem Vorwort zu Teil II. Genau genommen rechnet man dazu auch den Teil I (betitelt: Dziady. Widowisko) - ein posthum veröffentlichtes Fragment, geplant wahrscheinlich als Vorgeschichte von Gustav und seiner Geliebten, chronologisch jedoch erst nach dem Teil II entstanden und durch den späteren Teil IV ersetzt. Die „Konrad-Dichtung“ umfasst den Dresdener Teil III mit Vorwort sowie den Epischen Abstand (Ustęp) und die landeskundlichen Anmerkungen des Dichters.

${ }^{4}$ Vgl. Stefania Skwarczyńska: Struktura świata poetyckiego w Dziadach Mickiewicza. In: Dies.: Studia i szkice literackie. Warszawa 1953. S. 239.

${ }^{5}$ Teil II steht in enger Verbindung mit den ein Jahr zuvor erschienenen Balladen und Romanzen, die ursprünglich eine Art Einführung in das Drama darstellen und mit ihm zusammen in einem Band publiziert werden sollten (vgl. Jarosław Maciejewski: Historia powstawania Dziadów litewskich. In: Ders.: Trzy szkice romantyczne. Poznań 1967).

${ }^{6}$ Einen Versuch, dieses Rätsel zu entschlüsseln, findet man z.B. in dem Aufsatz von Eligiusz Szymanis: Warum in die Dresdener Ahnenfeier des Dramas dritter Teil? In: Adam Mickiewicz und die Deutschen. Eine Tagung im Deutschen Literaturarchiv Marbach am Neckar. Hg. von Ewa MazurKębłowska und Ulrich Ott. Wiesbaden 2000.

${ }^{7}$ Vgl. Zofia Stefanowska: Próba zdrowego rozumu. In: Dies.: Próba zdrowego rozumu. Studia o Mickiewiczu. Warszawa 2001 (1. Ausgabe: 1976). S. 45 f.
} 
Mickiewicz, die rätselhafte Nummerierung des Zyklus beizubehalten - mehr noch: Teil III selbst besteht aus einem einzigen Aufzug, was seinen fragmentarischen Charakter andeutet. Was der junge Autor in einer Selbstkritik noch als poetische Unzulänglichkeit beurteilte, wusste der reife Dichter mit Absicht zu vertiefen, zu funktionalisieren und zu einem grundlegenden Merkmal seines Werkes zu machen.

Mickiewicz war sein Leben lang bemüht, den bruchstückhaften, fragmentarischen Text ohne inneren kausalen Zusammenhang nachträglich $\mathrm{zu}$ einer neuen Ganzheit, zu seinem ,einzigen Werk, das des Lesens wert ist" umzugestalten. ${ }^{8}$ Alle Versuche, eine Fortsetzung von Teil III zu schreiben oder rückwirkend innere Kohärenz zu erzeugen, schlugen allerdings fehl. In der Idee einer einheitlichen, organischen Dichtung, eines künftigen Meisterwerkes, die den Dichter bis in seine späten Lebensjahre hinein begleitete, kam sein privates Drama als Schöpfer zum Ausdruck: Ein „unendliches“, „offenes” Werk zu einem vollendeten und „geschlossenen" zu machen und das romantisch Fragmentarische durch das klassisch Vollkommene zu ersetzen, erwies sich als Utopie. ${ }^{9}$ Das ,gedankliche Projekt" einer neuen Dziady-Dichtung, eines opus magnum, das alle früheren, auch unfertigen Dramenteile gleichsam verschlingen würde, erinnert übrigens an das Konzept der „neuen Poesie“ von Novalis und erwies sich in der Praxis als ähnlich fruchtlos. ${ }^{10}$

So viel zum heutigen Standpunkt der Mickiewicz-Forschung. Die Überzeugung, dass die Idee eines organischen Werkes gescheitert sei, scheint aber nicht ganz zutreffend zu sein. Zu dem Schluss gelangt man, wenn man Dziady ausschließlich unter dem Aspekt des Bedeutungsaufbaus betrachtet und versucht, dem Kompositionsprinzip des Dramas auf den Grund zu kommen - sei es durch Erforschung genetischer und biographischer Zusammenhänge, sei es, indem man den positivistischen Ansatz verwirft und, anstatt „Lücken“ und „Widersprüche“ in der Gesamtstruktur aufzuspüren, ,das Logische im Unlogischen“ findet und sich das Drama als ein nach eigenen Prinzipien geordnetes, zyklisch aufgebautes Werk erschließt. ${ }^{11}$ Wir sind jedoch der Meinung, dass die Untersuchung der Komposition allein das im Werk enthaltene Deutungspotential nur in begrenztem Umfang freisetzen kann und letztendlich in eine Sackgasse führt, da es immer Elemente gibt, die ins jeweilige Sinngebungskonzept nicht hineinpassen. Das Finden einer übergreifenden Kompositionsidee wird erschwert durch die simple Tatsache, dass unter dem gemeinsamen Titel Dziady grundverschiedene literarische Formen und Gat-

${ }^{8}$ Dies geht aus der Vorbemerkung Mickiewiczs zu der Sammelausgabe seiner Schriften aus dem Jahre 1844 hervor - vgl. Wacław Borowy: Zagadkowość kompozycji Dziadów i próba jej wyjaśnienia. In: Ders.: Studia i rozprawy. Bd.1. Wrocław 1952. S. 163.

${ }^{9}$ Vgl. S. Skwarczyńska, op.cit., S. 221 sowie Zofia Trojanowiczowa: Dziady jako ,niedokończony poemat". In: Trzynaście arcydziet romantycznych. Hg. von Elżbieta Kiślak und Marek Gumkowski. Warszawa 1996. S. 56.

${ }^{10} \mathrm{Vgl}$. Z. Trojanowiczowa, op.cit., S. 54.

${ }^{11}$ So etwa die Interpretation von Rolf Fieguth in: Drei Studien zur Dziady-Dichtung. In: Ders.: Verzweigungen. Zyklische und assoziative Kompositionsformen im dichterischen Werk von Adam Mickiewicz. Fribourg 1998. 
tungen vereinigt sind: Drama, lyrischer Monolog, Oper mit Arien und Rezitativen (in Teil II), epische Dichtung (Ustęp - 'Epischer Abstand' zu Teil III), Ballade, Volkslieder, philosophische Ode, Sachtexte (die beiden Vorworte zu Teil II und III, Anmerkungen zu Teil III). Gerade aber in der inneren gattungsmäßigen Heterogenität drückt sich die Vorstellung von einer organischen Dichtung aus; sie zeugt davon, dass Mickiewicz alle Formen der Poesie - des künstlerischen Schaffens überhaupt - als Ganzheit betrachtete, gleichsam als Spiegelbild der Einheitlichkeit der Welt. Die romantische Idee, das Universum bilde eine Kontinuität - das Endliche und das Unendliche, Vergangenheit, Gegenwart und Zukunft, das Dies- und das Jenseits - findet man in Ansätzen schon in Mickiewiczs Balladen und Romanzen. Sowohl in den Wilnaer als auch den Dresdener Dziady kommt sie in aller Deutlichkeit zum Tragen.

$\mathrm{Da}$ also der Begriff der Komposition in diesem Fall für Interpretationszwecke unzureichend bzw. begrenzt anwendbar ist, scheint es angebracht, ihn durch eine aufschlussreichere Kategorie zu ersetzen. Damit greifen wir gewissermaßen auf Erkenntnisse der älteren Mickiewicz-Forschung (z.T. aus dem 19. Jh.) zurück, die nach einer „verbindenden Grundidee“ suchte. ${ }^{12}$ Auf diese Grundidee, die im Folgenden als Weltbild bezeichnet sei, weist Mickiewicz indirekt selbst hin, freilich ohne die Formel einzusetzen. In seinen Bemühungen um die Sinngebung von Dzia$d y$ versuchte der Dichter, inneren Zusammenhang zwischen den einzelnen Dramenfragmenten nicht nur textimmanent, sondern auch metatextuell zu schaffen. Eine häufig übersehene und doch wertvolle Interpretationshilfe findet man in Selbstkommentaren des Autors. Dazu gehört ein Aufsatz, der als Vorwort des Verfassers zur französischen Übersetzung von Dziady (1834) geplant war. ${ }^{13}$ Die Hauptidee, gleichsam den gemeinsamen Nenner für die unter verschiedenen literarischen, biographischen und politischen Umständen verfassten Dramenteile - fügen wir hinzu: die Grundidee, die das Weltbild der Dichtung konstituiert - legt Mickiewicz folgendermaßen aus: Es sei „der Glaube an die Einwirkung der unsichtbaren, immateriellen Welt auf die Sphäre der menschlichen Gedanken und des menschlichen Wirkens. (...) Das volkstümliche Ritual der Totenfeier, die Geisterbeschwörung, die alle Hauptpersonen des Dramas erneut zusammenkommen lässt, verbindet die Handlung zu einer Einheit." ${ }^{\prime 4}$

Dieser Formulierung ist einerseits die bereits angesprochene Überzeugung abzulesen, dass alle Formen des Seins ein Kontinuum darstellen. Andererseits aber spricht hier Mickiewicz eine religiöse Vorstellung an, die etwa den Protestanten vollkommen fremd und für damalige wie heutige Westeuropäer schwer verständlich

\footnotetext{
${ }^{12}$ Beispiele für die „Grundidee” von Dziady aus dem 19. Jh.: s. Jerzy Kreczmar: Problematyka sceniczna Dziadów. In: Ders.: Stare - nieprzestarzałe. Warszawa 1989. S. 205.

${ }^{13}$ Vgl. W. Borowy, op.cit., S. 163 sowie J. Maciejewski, op.cit., S.142 und die Anmerkung 250 auf S. 278.

${ }^{14}$ Zitiert nach: Ryszard Przybylski: Stowo i milczenie bohatera Polaków. Studium o Dziadach. Warszawa 1993. S.7. (Übersetzung: K.L.)
} 
ist: das katholische Dogma von der Gemeinschaft der Heiligen, bekräftigt durch die unter dem orthodoxen weißrussischen Volk gepflegte Überzeugung, dass die Lebendigen den im Fegefeuer leidenden Seelen durch Fürbitte, Mildtätigkeit und Almosen Erleichterung verschaffen können. ${ }^{15}$ Das Ritual der Totenbeschwörung hat an sich zwar vorchristliche Wurzeln, ist aber - wie so viele heidnische Bräuche von der Kirche angeeignet worden. Im Grunde ist also die gesamte DziadyDichtung eine Manifestierung des Glaubens an das Fegefeuer und somit an die Liebe Gottes, der auch Sünder auf Erlösung vertrauen lässt. ${ }^{16}$ Die beiden Komponenten: das romantische Paradigma und der katholische Glaube, verwachsen mit Vorstellungen der orthodoxen Kirche, bestimmen somit das Weltbild von Dziady.

Als ein weiteres verbindendes Element seines Werkes nennt Mickiewicz in dem vorgenannten Metatext den Hauptprotagonisten: „Eine gewisse Einheitlichkeit verleiht dem Werk eine geheimnisvolle Persönlichkeit, die im gesamten Drama wiederholt erscheint." 17 Der Protagonist fungiert als Träger des im dramatischen Fragment kodierten Weltbildes, wobei seine Rolle u.E. am deutlichsten im Teil IV zur Geltung kommt.

In der Mickiewicz-Forschung gilt das Kernstück der „Gustav-Dichtung“ als ein erster Höhepunkt der polnischen Frühromantik, ein Werk, das die romantische Poetik realisiert. Für Wacław Borowy handelt es sich dabei um eine Vision, einen Traum, der nach anderen Grundsätzen konstruiert wird als die durchaus realistischen Teile II und III. Die onirische Poetik hebt die Grenze zwischen Traum und Wirklichkeit auf, erlaubt eine inkonsequente, widersprüchliche Gestaltung der Protagonisten und der dargestellten Welt und bietet eine Erklärung für die „unlogische“ Nummerierung der Dramenteile. ${ }^{18}$ Rolf Fieguth betont die rein assoziative, die alogische Struktur des menschlichen Gedächtnisses nachahmende Komposition von Teil IV. ${ }^{19}$ Und schließlich steht der fragmentarische Aufbau der gesamten „GustavDichtung“ ebenfalls im Zeichen der Romantik: Die Konvention des literarischen

${ }^{15}$ Über den Wilnaer Teil von Dziady im Kontext der eschatologischen Vorstellungen der orthodoxen Kirche sowie über die Entwicklung dieser Vorstellungen bei der Bevölkerung im polnischweißrussischen Grenzgebiet unter dem Einfluss der römisch-katholischen, griechisch-unierten und orthodoxen Kirche vgl. Stanisław Pigoń: Formowanie Dziadów części drugiej. Rekonstrukcja genetyczna. Warszawa 1967. S. 15 f. - Zu der Lehre über das Fegefeuer, die Gemeinschaft der Heiligen sowie zu den Unterschieden zwischen der katholischen, orthodoxen und evangelischen Dogmatik vgl. z.B. Lexikon für Theologie und Kirche. Zweite, neubearbeitete Auflage des kirchlichen Handlexikons. Hg. von Dr. Michael Buchberger. Freiburg i. Br. 1932. Bd. 3, S. 979 ff. und Bd.4, S. 364; Encyklopedia chrześcijaństwa. Historia $i$ wspótczesność - 2000 lat nadziei. Kielce 2000 (2001). Hg. von Henryk Witczyk u.a. S.156 f.; Encyklopedia katolicka. Hg. von Romuald Łukaszyk, Ludomir Bieńkowski, Feliks Gryglewicz. Bd. III. Lublin 1989. S. 939 ff.

${ }^{16}$ Vgl. R. Przybylski, op.cit., S. 91 .

${ }^{17}$ Ebda, S. 7.

${ }^{18}$ Vgl. W. Borowy, op.cit., S. 185.

${ }^{19}$ R. Fieguth, op.cit., S. 295. 
Fragments reicht bekanntlich bis ins 18. Jahrhundert zurück und wurde u.a. von deutschen Romantikern fortgesetzt. ${ }^{20}$

$\mathrm{Zu}$ den formal romantischen Merkmalen kommt in Teil IV noch hinzu, dass hier zum ersten Mal in der polnischen Literatur ein in mancher Hinsicht romantischer Held zu Wort kommt - romantisch nicht durch seine tragische Liebesgeschichte (dieses Motiv wurzelt noch stark in der Empfindsamkeit), sondern kraft seines unklaren, ambivalenten ontologischen Status, der ihn zu einem nahen Verwandten der Figuren der deutschen Romantik macht. Diese Person verkörpert aber auch das religiöse Element des von Mickiewicz entworfenen Weltbildes. Durch seine Zugehörigkeit zu den Lebendigen und Toten zugleich wird Gustav zum Sinnbild der Einheit von Dies- und Jenseits und der Gemeinschaft der Heiligen. Sein Appell, das verbotene Fest der dziady, die Ahnenfeier, wieder begehen zu lassen, ist als dramatisches Bekenntnis zum katholischen Dogma zu verstehen. Eine wesentliche Funktion erfüllen Gustavs Erinnerungen und assoziative Gedankengänge, die sich beinahe zu einem stream of consciousness zusammenfügen: Sie verdeutlichen die Totalität der Zeit, das Ineinanderfließen von Einst und Jetzt. In dem ontologischen Status der literarischen Hauptfigur und in ihren Erinnerungen findet somit das Weltbild des dramatischen Fragments seinen Niederschlag.

Da die Aufgabe des Übersetzers eines jeden literarischen Werkes eben darin besteht, nicht bloß Wörter und Sätze, sondern das Weltbild des Ausgangstextes zu übertragen, ${ }^{21}$ wollen wir in nachstehender Analyse ermitteln, wie das romantischkatholisch vorbestimmte Weltbild von Dziady, das am Protagonisten von Teil IV erkennbar ist, im Original und in den vorhandenen deutschsprachigen Übersetzungen aufgebaut wird.

\subsection{Deutschsprachige Übersetzungen von Dziady}

Die Aufnahme von Dziady im deutschen Sprachraum verlief anders als bei den meisten Mickiewicz-Werken, von denen fast jedes bald nach der Entstehung seine komplette deutsche Nachdichtung erhielt. Seit der Veröffentlichung der beiden Wilnaer Teile war das Werk durch relativ viele Teilübersetzungen im Bewusstsein

${ }^{20}$ Als mögliche Bezugspunkte dazu nennt Wacław Borowy u.a. den „lückenhaften“ Roman von Laurence Sterne Tristram Shandy, die bruchstückhaften, das Volkstümliche vortäuschenden OssianLieder und - in der deutschen Literatur - etwa Jean Pauls quasi unvollendeten Roman Biographische Belustigungen unter der Hirnschale einer Riesin, aus dem Mickiewicz übrigens ein Zitat als Motto für den Teil IV von Dziady auswählt (vgl. Wacław Borowy, op.cit., S. 157 f.).

${ }^{21}$ Vgl. Stefan H. Kaszyński: Vom Übersetzen der Weltbilder. Essay über die Rolle der literarischen Übersetzer im europäischen Gedankenaustausch. S. 11, sowie Maria Krysztofiak: Übersetzungskritik im Spannungsfeld der Literaturkritik. S. 204. Beide Aufsätze in: Studia Germanica Posnaniensia XXIX. Probleme der literarischen Übersetzung. Hg. von Maria Krysztofiak-Kaszyńska. Poznań 2003. 
deutscher Leser präsent (und das mehr noch im 19. als im 20. Jahrhundert). ${ }^{22}$ Trotzdem musste das dramatische Fragment bis 1887 auf eine vollständige Nachdichtung warten, die von Siegfried Lipiner stammt und jahrelang als unübertrefflich galt. ${ }^{23}$ 1967 entstand die - ausdrücklich als Rohübersetzung bezeichnete - Bühnenbearbeitung der Dziady, die Gerda Leber-Hagenau für eine nicht zustande gekommene Aufführung am Wiener Burgtheater vorbereitete und schließlich erst 1998 (zu Mikkiewiczs 200. Geburtstag) im Druck erscheinen ließ. ${ }^{24} 1991$ verfasste der Slawist Walter Schamschula seine besonders sorgfältige, philologische Übertragung, die zusammen mit dem polnischen Text synoptisch herausgegeben wurde. ${ }^{25}$

Wegen der jahrzehntelang herrschenden, auch von Mickiewicz vertretenen Überzeugung von der Unaufführbarkeit romantischer Dramen im Rahmen des konventionellen Theaters des 19. Jh. fungierte das Fragment Dziady bis zum ersten ganzheitlichen Inszenierungsversuch von Stanisław Wyspiański (1901) als zwei separate, für ganz unterschiedliche Gruppen von Rezipienten bestimmte Parallelwerke: einerseits als Lese-, andererseits als Bühnentext. ${ }^{26}$ Dabei lebt der Letztere gleichsam sein eigenes Leben und wird verschiedensten Regiekonzepten unterworfen. Jede Aufführung fordert das Deutungspotential des Dramas aufs Neue, jeder Regisseur erweitert mit seinen konkreten szenischen Lösungen die gültigen, auf philologischer Basis erarbeiteten Interpretationen. ${ }^{27}$ Übrigens bestehen in dieser Hinsicht zahlreiche Gemeinsamkeiten und Berührungspunkte zwischen Inszenierung und Übersetzung.

${ }^{22}$ Vgl. Brigitte Schultze: Ein Fall selektiven Kulturtransfers: Die „Improvisation“ im III. Teil von Mickiewiczs Dziady in deutschen Übersetzungen. In: Balten - Slaven - Deutsche: Aspekte und Perspektiven kultureller Kontakte. Festschrift für Friedrich Scholz zum 70. Geburtstag. Hg. von Ulrich Obst und Gerhard Ressel, unter Mitarbeit von Monika Glaser und Astrid Müncho. Münster 1999. S. $277 \mathrm{f}$. $\mathrm{Zu}$ deutschen Übersetzungen von Dziady aus den 20er und 30er Jahren des 19. Jh. s. auch Stanisław Łempicki: Nieznany najdawniejszy przekład Dziadów wileńskich na język niemiecki (1829). In: Ders.: Wiek złoty i czasy romantyzmu w Polsce. Warszawa 1992. S. 645f.

${ }^{23}$ Poetische Werke von Adam Mickiewicz. Band II: Todtenfeier (Dziady). Übersetzt und mit erklärender Einleitung versehen von Siegfried Lipiner. Leipzig 1887. Alle Zitate aus dieser Ausgabe sind im Folgenden mit SL und Seitenzahl gekennzeichnet.

${ }_{242}$ Gerda Hagenau: Adam Mickiewicz als Dramatiker. Dichtung und Bühnengeschichte. DziadyTotenfeier. Deutsche Übersetzung. Frankfurt/M. 1999 (=Europäische Hochschulschriften. Reihe XVI: Slawische Sprachen und Literaturen. Bd. 61). Alle Zitate aus dieser Ausgabe sind im Folgenden mit $\mathrm{GH}$ und Seitenzahl gekennzeichnet.

${ }^{25}$ Adam Mickiewicz: Die Ahnenfeier. Ein Poem. Zweisprachige Ausgabe. Übersetzt, herausgegeben und mit einem Nachwort versehen von Walter Schamschula. Mit einem Vorwort von Hans Rothe. Köln - Weimar - Wien 1991 (=Schriften des Komitees der Bundesrepublik Deutschland zur Förderung der Slawischen Studien; 14). Alle Zitate aus dieser Ausgabe sind im Folgenden mit WS und Seitenzahl gekennzeichnet.

${ }^{26} \mathrm{Vgl}$. Dobrochna Ratajczakowa: „Zamknijcie drzwi od kaplicy...”. In: Księga Mickiewiczowska. Patronowi uczelni $w$ dwusetna rocznice urodzin 1798-1998. Hg. von Zofia Trojanowiczowa und Zbigniew Przychodniak. Poznań 1998. S. 80).

${ }^{27}$ Vgl. Zbigniew Majchrowski: Dziady jako arcydzieto w ruchu. In: Trzynaście arcydziet romantycznych. Hg. von Elżbieta Kiślak und Marek Gumkowski. Warszawa 1996. S. 57. Die berühmtesten Regiekonzepte von Stanisław Wyspiański oder Leon Schiller, die jedes einer für ihre Epoche mustergültigen Aufführung zugrunde lagen, haben sich im Laufe der Zeit verselbständigt, so dass man heute über die Dziady von Wyspiański oder die Dziady von Schiller spricht. 
Nach den beiden Rezeptionsarten, die von der Doppelfunktion des dramatischen Fragments Dziady in der polnischen Literaturgeschichte und im polnischen Kulturleben gesteuert werden, richten sich auch die Übersetzungen. Die Nachdichtungen von Lipiner und Schamschula sind ausschließlich für die Lektüre bestimmt. Die Möglichkeit einer Theateraufführung wurde weder 1887 noch 1991 mitgedacht, wenn auch aus verschiedenen Gründen. Lipiner konnte sich noch an keiner erfolgreichen Aufführung in Polen orientieren ${ }^{28}$ und ging notgedrungen von der Unaufführbarkeit der Mickiewicz'schen Vorlage aus. In seinem Vorwort bezeichnet er Dziady konsequent als Dichtung und nicht als Drama. Außerdem war dem Übersetzer bewusst, dass er das Hauptwerk der polnischen Romantik dem deutschen Lesepublikum zum ersten Mal in einer kompletten Gestalt erschließt. Damit lassen sich bestimmte Vereinfachungen des Originals erklären, die Lipiner in seiner Fassung der Verständlichkeit halber vornimmt. ${ }^{29}$

Die weitgehend interlineare Übersetzung Schamschulas erhebt Anspruch auf Vollständigkeit und philologische Treue und ist ebenfalls zum Lesen gedacht. Im Unterschied zu seinem Vorgänger ist aber Schamschula von der Last der Pionierrolle befreit, was ihm erlaubt, eine solche Fassung anzustreben, die als Quellentext z.B. für deutsche Slawisten dienen könnte. Daher behält er den ursprünglichen Aufbau, die Nummerierung der Dramenteile und den gesamten Metatext bei.

Die Bühnenfassung G. Hagenaus ist nach ganz anderen Prinzipien gestaltet. Die Übersetzerin musste vom Theater als spezifischem Medium des Literatur- und Kulturtransfers ausgehen und die Rezeptionsbereitschaft der zielseitigen Zuschauer stets im Hinterkopf behalten. Damit der Handlungsablauf möglichst wenig Lücken und Unklarheiten aufweist, hat sie die Reihenfolge der einzelnen Dramenteile umgestellt, deswegen geht der Teil IV dem Teil II voran. Im Übrigen unterlag die Übersetzerin demselben Zwang wie jeder polnische Regisseur von Dziady: Sie musste ihre Vorlage dem zeitlichen Rahmen eines Theaterabends anpassen. Daraus ergibt sich, dass der Schwerpunkt ihrer Übertragung genauso wie bei so manchen berühmten Inszenierungen auf Teil III liegt (trotz der von G. Hagenau abgegebenen Erklärung, das Politische zugunsten des Allgemein-Menschlichen auszublenden ${ }^{30}$ ), während das Kernstück der „Gustav-Dichtung“ - Teil IV - zu einer stark gekürzten

${ }^{28}$ Mit Ausnahme einzelner Szenen oder Ausschnitte aus Teil II, der in der Vertonung von Stanisław Moniuszko (als Kantate Widma) bereits 1865 zur Aufführung gelangte (vgl. Encyklopedia muzyczna PWM. Czesść biograficzna. Hg. von Elżbieta Dziębowska. Warszawa 2000. S.323), funktionierte das dramatische Fragment im 19. Jh. noch nicht als Theatertext.

${ }^{29}$ Lipiner war es klar, dass das selbst für die Gattung des romantischen Dramas ungewöhnlich aufgebaute Werk die Aufnahmefähigkeit der Zielleser überfordern könnte. Die Änderung der ursprünglichen Nummerierung der Dramenteile begründet er wie folgt: „Ich sah nicht ein, warum ich in Einem Werke, das dem deutschen Leser ohnehin des Fremdartigen genug bietet, noch das Unsinnige und Verwirrende einer solchen Eintheilung beibehalten sollte. Ich habe demnach II. und IV. zusammengefügt und sie: zweiten Theiles erste und zweite Abtheilung genannt, - was sie thatsächlich sind. Diesen folgt nun in natürlicher Ordnung die Konrad-Dichtung, - wie im Original als: der „Todtenfeier“ dritter Theil bezeichnet.“ (S. Lipiner: Einleitung. Zur Erklärung der „Todtenfeier”. In: Poetische Werke von Adam Mickiewicz..., op.cit., S. IX).

${ }^{30} \mathrm{Vgl}$. Gerda Hagenau: Adam Mickiewicz als Dramatiker. Dichtung und Bühnengeschichte, op.cit., S.7f. sowie S. 167. 
Einzelszene zugeschnitten wird und dem tief ergreifenden psychologischen Drama Gustavs nur wenig Platz übrig lässt. Teil IV ist übrigens noch nie vollständig bzw. als separates Bühnenwerk aufgeführt worden, ${ }^{31}$ was auf seine textimmanenten Merkmale zurückzuführen ist: die größtenteils aus lyrischen Monologen bestehende Dichtung eignet sich im Grunde - trotz durchaus theaterwirksamer Effekte wie von allein verlöschenden Kerzen, der schlagenden Uhr u. Ä. - nicht für die Bühne und erfüllt in viel höherem Maße als Teil II und III die Voraussetzungen dafür, ausschließlich Lektüre zu bleiben. Deswegen geht Teil IV in der Nachdichtung von G. Hagenau schlichtweg unter.

An dieser Stelle ist noch eine Vorbemerkung notwendig. Es ist unumstritten, dass alle drei deutschsprachigen Fassungen uns heute nur als Lektüre vorliegen unabhängig von den Zwecken und Zielvorstellungen, die ihre Übersetzer verfolgten. Deswegen wollen wir sie auch als Lese- und nicht als Bühnentexte betrachten, d.h. aus der Perspektive des Lesers und nicht des virtuellen Zuschauers. Welche der drei Nachdichtungen das größte theatrale Potential besitzt, bleibt hier dahingestellt. Darüber hinaus gelten uns die deutschen Übertragungen als fe rt ige und vollgültige Zieltexte und nicht als „Übergangsversionen“. Diese Bemerkung bezieht sich in erster Linie auf die Fassung von G. Hagenau. Die Einschränkung der Übersetzerin, sie habe lediglich die Grundlage für eine Theatervorstellung geliefert, die entsprechend dem jeweiligen Regiekonzept noch gekürzt und gestrichen werden müsse, wurde durch ihre Entscheidung, den Text in der Gestalt aus den 60er Jahren doch zu veröffentlichen, gleichsam aufgehoben. Einzelne übersetzerische Lösungen lassen sich zwar in diesem Fall damit begründen, dass die Verfasserin die szenische Wirklichkeit oder „Spielbarkeit“ der Originalvorlage mitberücksichtigte. Wir wollen allerdings nicht spekulieren, was sie an ihrer Bearbeitung noch hätte ändern können. Viel aufschlussreicher ist es zu verfolgen, wie sich die vorgenommenen Kürzungen auf den endgültigen Zieltext auswirken.

\section{Die ,geheimnisvolle Persönlichkeit" im IV.Teil von Dziady}

\subsection{Das Moment der ontologischen Ambivalenz}

Die im gesamten Werk stets präsente ,geheimnisvolle Persönlichkeit”, auf die Mickiewicz selbst hinweist, ist hinsichtlich ihres ontologischen Status äußerst umstritten. Die Hauptgestalt aller Teile des dramatischen Fragments wird immer wieder auf mehrere Persönlichkeiten verteilt, so dass sie als eine diffuse, zersplitterte Figur erscheint. Die meisten Forscher interpretieren sie als ein und dieselbe Person. ${ }^{32}$ Wäh-

${ }^{31}$ Vgl. J. Kreczmar, op.cit., S. 249 und 254.

${ }^{32}$ R. Przybylski etwa nennt diese Figur „den Helden der Polen” (in: op.cit.). Das Verzeichnis der dramatis personae, das der Bühnenfassung von Gerda Hagenau voransteht, enthält den Hinweis, dass Konrad, Gustav, Eremit, Gespenst und Gefangener vom gleichen Schauspieler darzustellen sind. 
rend aber im Teil III grundsätzlich kein Zweifel daran besteht, dass der Gefangene im Prolog, der Dichter Konrad im I. Akt und der Pilger im Epischen Abstand für denselben Protagonisten stehen, wird uns in den Wilnaer Dziady die Identität zwischen Gustav, dem Gespenst aus der Eröffnungsballade und dem „schweigenden Gespenst” im II. Teil „Zwar suggeriert, aber keineswegs garantiert (...). Es bestehen jedenfalls nicht wenige Widersprüche zwischen diesen drei Figuren, welche die Identität einer einzigen Figur zu beanspruchen scheinen." ${ }^{33}$ Auch wenn man allein den hier zu untersuchenden Teil IV betrachtet, erhält man keine eindeutige Antwort auf die Frage: Wer ist diese Gestalt? Ein Gespenst eines Selbstmörders aus unglücklicher Liebe? Ein lebendiger, wahnsinnig gewordener Mensch? Ein Schatten eines Lebendigen $?^{34}$

Mit Recht behauptet Rolf Fieguth, dass ,auf der Ebene der fiktionalen Welt eine Konkurrenz zweier gleichzeitiger Versionen der Hauptgestalt erzeugt wird: einer diesseitigen und einer jenseitigen Version" ${ }^{35}$ Dabei ist die Figur Gustavs so aufgebaut, dass beide Versionen legitim und gleichberechtigt sind: Gustav muss ein lebendiger Mensch sein, damit seine Leiden als psychologisch glaubwürdig erscheinen und eine überzeugende dramatische Wirkung erzielen; er muss aber zugleich tot sein, da nur ein Selbstmord, dem kein Tod folgt, die vernünftige, aufklärerische Weltanschauung erschüttern kann. ${ }^{36}$ Das perfekte Gleichgewicht zwischen dem „irdischen“ und ,"̈̈berirdischen“ Moment spiegelt das Kontinuum von Diesseits und Jenseits als Bestandteil des romantischen Weltbildes der Dziady wider. Zudem ist die Person Gustavs ein Beweis für die katholische Vorstellung von der geistigen Anwesenheit der Verstorbenen unter den Lebendigen. Von der Bewahrung der doppelten ontologischen Verankerung Gustavs hängt in hohem Maße ab, inwieweit das Weltbild der Dziady in der Zielsprache erfolgreich nachgebildet wird.

Das ständige Oszillieren zwischen der „Diesseitigkeit“ und „Jenseitigkeit“ des Hauptprotagonisten richtet sich nach dem Verlauf seiner Polemik mit dem Priester - einem Verfechter der Ratio - und erweist sich als Mittel, dessen Glauben an den gesunden Menschenverstand zu kompromittieren; gerade weil der Priester nicht an Gespenster glaubt und sich gegen jeglichen Aberglauben wehrt, wird sein Gast zu einem Gespenst. ${ }^{37}$ Den gesamten Teil IV beherrscht Gustavs gewaltiger Redefluss, den die spärlichen Kommentare und Zwischenrufe seines gutmütigen Gesprächspartners weder zu lenken noch zu unterbrechen imstande sind. Der „Einsiedler“ führt mit dem Priester ein raffiniertes psychologisches Spiel: Mit seinen ersten Worten provoziert er Zweifel an seinem ontologischen Status, die er durch absichtlich doppeldeutige Formulierungen verstärkt, um sie anschließend wieder zu relati-

${ }^{32}$ R. Fieguth, op.cit., S. 234.

${ }^{34} \mathrm{Vgl}$. das Stichwort Gustaw-Konrad in: Jarosław Marek Rymkiewicz, Dorota Siwicka, Alina Witkowska, Marta Zielińska: Mickiewicz. Encyklopedia. Warszawa 2001. S. 179 f.

${ }^{35}$ R. Fieguth, op.cit., S. 238.

${ }^{36}$ Vgl. Z. Stefanowska, op.cit., S. 63.

${ }^{37}$ Vgl. Z. Stefanowska, op.cit., S. 62 f. 
vieren. Die zunächst nur metaphorisch gemeinten Hinweise auf Gustavs Identität gewinnen allerdings zunehmend an seltsamer Wörtlichkeit. Ungeachtet dessen legt der Priester die unheimlichen, für den Leser beklemmenden Aussagen des Hauptprotagonisten konsequent rationalistisch aus, bis er letztendlich bei Gustavs folgenlosem Selbstmord die Unzulänglichkeit der aufgeklärten Vernunft erkennen muss.

Im Folgenden wollen wir diejenigen Textstellen mit ihren Übersetzungen vergleichen, die den ontologischen Status Gustavs andeuten, um aufzuzeigen, inwieweit die deutschen Fassungen die Ambivalenz der Hauptgestalt an den Tag legen. Größtenteils handelt es sich um die Aussagen Gustavs über sich selbst. Gleich mit seinem Erscheinen in der Pfarrstube beginnt der merkwürdige Gast, spärliche Informationen zu seiner Identität wirkungsvoll zu dosieren:

\section{Schamschula:}

DZIECI: Ach, trup, trup! upiór, ladaco!

W imię Ojca!... zgiń, przepadaj! (...)

PUSTELNIK: Trup... trup!... tak jest, moje dziecię. (...)

Umarły!... o nie! tylko umarły dla świata!

Jestem pustelnik, czy mnie rozumiecie? (AM $40^{38}$ )

Lipiner:

G. Hagenau:

DIE KINDER. Ein Leichnam! Leichnam! Ein KINDER: Ach, ein Toter! Ein Toter! Ein Vampir! Nichts Gutes -

Gespenst!

Gott sei bei uns! Ach, ach - versink! vergeh’! Im Namen des Vaters! ... Geh fort! Verschwin-

(...)

de!

(...)

EINSIEDLER. Ja! Ein Leichnam - Leichnam - Ja, so ist's, mein Kind! (...)

Ein Todter? - Nein, o nein - der Welt nur todt; Ich bin ein Einsiedler, versteht ihr mich? (SL 54)

EREMIT: Ein Toter... Ein Toter! ... jawohl, meine Kinder. (...)

Ein Toter!... Oh nein! Nur tot für die Welt!

Ich bin ein Eremit, versteht ihr, was das ist?

(GH 194)

Nach romantischer Auffassung war der Einblick in das wahre Wesen der Dinge besonders Kindern gegeben. Die Kinder des (griechisch-unierten) Priesters glauben in dem seltsamen Fremdling sofort einen Toten $\mathrm{zu}$ erkennen. Dem stimmt Gustav zu, überträgt es aber gleich auf die metaphorische Ebene: Er sei „nur für die Welt“ ein Toter. Die Kinder bezeichnen ihn außerdem als upiór (,Gespenst“). An dieser

${ }^{38}$ Adam Mickiewicz: Dzieła. Wydanie Narodowe. Bd. III: Utwory dramatyczne. Hg. von Stanisław Pigoń. Warszawa 1949. Alle Zitate aus dieser Ausgabe sind im Folgenden mit AM und Seitenzahl gekennzeichnet. 
Stelle lesen wir sowohl bei Lipiner als auch bei Schamschula das Wort Vampir. Es korrespondiert mit dem Titel der Eröffnungsballade Upiór, für den beide Übersetzer diese Entsprechung finden. Vampir hat aber einen anderen Konnotationswert als der Mickiewicz'sche upiór, auch wenn beide phantastischen Gestalten dem Volksglauben entstammen. Ein Vampir greift die Lebendigen an, während Gustav durchaus keine bösen Absichten hat; er will nur sein Leid noch einmal erleben und ins „Land der Erinnerungen" zurückkehren. Der Begriff Vampir trivialisiert die komplexe Gestalt des Protagonisten durch mögliche unerwünschte Assoziationen mit Dracula und steuert die Aufmerksamkeit des Lesers in Richtung einer sensationell aufgemachten Gruselgeschichte im Stil der (übrigens von Mickiewicz in seinen Balladen und Romanzen verpönten) Schauerromantik. Die Übersetzung von Gerda Hagenau (Gespenst) kommt in dieser Hinsicht dem Original näher als die beiden anderen Texte.

Nach seiner Identität befragt, verweigert der seltsame Gast eine eindeutige Antwort. Er versteckt sich hinter dem Namen eines "für die Welt gestorbenen“ Einsiedlers (pustelnik). An dieser Stelle kreuzen sich zum ersten Mal zwei leitmotivische Ketten der „Gustav-Dichtung“" „Leben vs. Tod“ und „Erinnern vs. Vergessen“. Vergessen bedeutet: vernichten, sterben lassen, wohingegen man in der Erinnerung bzw. durch ihre Macht weiter lebt. Beide Ketten verlaufen parallel und kreuzen sich an Wendepunkten des dramatischen Fragments. Das Bekenntnis des Einsiedlers, er sei „für die Welt gestorben“ - eines der Glieder dieser Kette - wird in den Übersetzungen nicht immer konsequent beibehalten:

Otóż ja także umarły dla świata. (...)

Nazwiska, (patrzy na zegar)

jeszcze rano... powiedzieć nie mogę;

Idę z daleka, nie wiem, z piekła czyli z raju,

I dążę do tegoż kraju. (AM 41)
Schamschula:

Fand auch ich den ewgen Frieden, - (...)

Meinen Namen... (schaut auf die Uhr)

es ist früh, muß schweigen,

Komm von fern, ob Himmel, Hölle, gilt mir gleich,

Heimwärts muß ich wieder in mein Reich. (WS $94 \mathrm{f}$.)

Lipiner: $\quad$ G. Hagenau:

Sieh', ich bin auch gestorben, für die Welt - Es ist noch zu früh... ich kann es nicht sagen, (...) Ich komme von weit her, ich weiß nicht, wo-

Der Name? - noch zu früh, - ich kann's nicht her, sagen.

Ob aus der Hölle, ob aus dem Himmel,

Fern komm’ ich her, - weiß nicht, ob aus der Ich eile dorthin zurück. (GH 194)

Hölle,

Ob aus dem Paradies - und geh' auch dahin:

(...) (SL 54) 
Die vorgenannte Mitteilung Gustavs erscheint explizit nur bei Lipiner. G. Hagenau lässt sie aus, so dass das Leitmotiv nicht nachvollziehbar ist. Schamschula lässt seinen Gustav den ewgen Frieden finden, was man nur als Tod verstehen kann. Mit der konventionellen Metapher aus der Kirchensprache erhält Gustavs Aussage einen im Original an dieser Stelle nicht vorhandenen religiösen Konnotationswert und zudem einen ironischen Beigeschmack: Die Gemütslage des Helden ist ja alles andere als friedlich und ausgeglichen, vielmehr wäre sie als chronischer Zustand psychischer Überspannung zu bezeichnen.

Als seinen Herkunftsort nennt Gustav Hölle oder Paradies, was sich doppelt auslegen lässt: im wörtlichen Sinne (wenn wir seine ,jenseitige“ Version als vordergründig annehmen) oder metaphorisch, als Zustand der Glückseligkeit oder des Leidens (wenn man den Helden als lebendigen Menschen interpretiert). Die Gegenüberstellung piekto - raj wird bei Lipiner wörtlich als Hölle - Paradies übersetzt, während Schamschula und Hagenau die etwas konventionellere Opposition Himmel - Hölle wählen. Die angeführte Passage kommt im Original zweimal fast unverändert vor, so dass sie dem Leser auffallen muss; die dabei ausgedrückte Ungewissheit des Protagonisten bezüglich seines ontologischen Status ist eines der ersten Signale seiner emotionalen Verwirrung und unzureichenden Urteilskraft, ein Zeichen, dass seine Wertmaßstäbe durcheinander geraten sind. Lipiner und G. Hagenau lassen Gustav dieses plagende Gefühl ausdrücken, bei der Wiederholung jedoch verändert die Übersetzerin den Text mit der Folge, dass die innere Zerrissenheit des Sprechenden verschwindet (Ich komme von weit her, aus der Hölle, oder aus dem Himmel). Schamschula dagegen vermittelt uns das Bild eines emotional gleichgültigen, abgestumpften Menschen: ob Himmel, Hölle gilt mir gleich. Das „Land“ (kraj) - das Ziel von Gustavs Wanderschaft - hat im Original eine unklare Bedeutung: Es kann sich dabei um die vorgenannte Alternative „Hölle“ vs. „Paradies“ handeln, genauso gut aber um das leitmotivische „Land der Erinnerungen“ (kraj pamiatek), d.h. die reale Gegend, die Gustav an seine Vergangenheit erinnert. Alle Übersetzer entscheiden sich hier für die erstere Interpretation. Schamschula erzielt mit der Formulierung mein Reich bzw. jenes Reich sogar religiöse Konnotationen, die bei der Wiederholung verstärkt zum Tragen kommen: [Ich] sehne mich nach jenem Reich legt nahe, dass der Sprechende nur ungern das Jenseits verlässt und Zuflucht zum Glauben und zur Religion nimmt. Alle deutschen Nachdichtungen sind an dieser Stelle im Vergleich mit dem Original eindeutiger und heben den ,jenseitigen Status“ des Protagonisten hervor.

Die Aufforderung Gustavs, sein Gastgeber solle ihm den Weg zum Tod zeigen (Pokaż ... wszak dobrze wiesz do śmierci drogę? - AM 43) ist einer der Wendepunkte im Dialog. Von nun an gibt sich der Priester alle Mühe, den verwirrten jungen Mann von seiner gottlosen Absicht abzubringen. Bei Lipiner und Hagenau ist diese Bitte genauso klar wie im Text von Mickiewicz: Den Weg zum Tod weißt du doch gut - so zeig' ihn! (SL 56), Zeig ihn mir... du kennst doch gut den Weg zum 
Tode? (GH 196). Der Gustav von Schamschula dagegen drückt sich verhüllend aus: Zeig ... du kennst gewiß den Weg zur Ewigkeit? (WS 98). Die Metapher: der Weg zur Ewigkeit muss nicht unbedingt bedeuten, dass der Held mit dem Selbstmordgedanken spielt; vielmehr scheint sie das Gespräch in Richtung eines eschatologischen Disputes zu lenken.

Nach Z. Stefanowska veranschauliche der IV. Teil von Dziady die Überzeugung, dass jegliche Versuche einer zwischenmenschlichen Kommunikation im Rahmen der üblichen gesellschaftlichen Umgangsformen zum Scheitern verurteilt sind. Nur durch Liebe könne man dem anderen seine wahren Gefühle mitteilen und dabei verstanden werden. ${ }^{39}$ Der Dialog zwischen Gustav und dem Priester, in dem beide Gesprächspartner aneinander vorbeireden, kompromittiert die Sprache als Verständigungsmittel. Auch als der Priester in dem nächtlichen Gast seinen früheren Lieblingsschüler erkennt, kommt kein richtiger Kontakt zustande. Die Szene der Wiedererkennung ist ein krasses Beispiel, wie der Priester für doppelsinnige Formulierungen Gustavs vollkommen taub bleibt:

\author{
Schamschula:
}

Ojcze, jeszcze ściskać mogę! $\quad$ Vater! noch kannst du mich grüßen,
Bo potem... wkrótce... zaraz pójdę w kraj Mich umarmen... aber bald schon ruft's mich daleki! von hier weit!

Ach, i ty będziesz musiał wybrać się w tę Ach, dann wirst auch du des Weges wandern drogę, müssen,

Uściśniemy się wtenczas, ale już na wieki!

(AM 72)

Dann umarmen wir uns für die Ewigkeit! (WS 147)

Lipiner:

Mein Vater! - Noch,

G. Hagenau:

Noch kann ich dich umarmen; denn hernach In Kurzem - gleich - geh' ich in fernes Land.

Vater, noch kann ich dich umarmen!

Denn dann... bald... gleich gehe ich wieder weit fort!

Ach, einst machst du auch diese Fahrt! Und Ach, auch du wirst einmal dorthin nachkomwieder men müssen,

Umarmen wir uns dann - doch dann auf ewig! Dann wollen wir einander in Ewigkeit umar(SL 80) men. (GH 206)

Der „Einsiedler“ aktiviert hier das metaphorische Begriffsfeld: kraj daleki (fernes Land) und droga (Weg). In diesem Zusammenhang erhalten diese - sonst ambivalenten - Lexeme die Bedeutung „das Jenseits“ und „der Weg zum Tod“ bzw. „nach dem Tod“, da Gustav zugleich von einer Umarmung „für immer“ spricht. Die eindringliche Metaphorik wird von Lipiner als fernes Land und Fahrt realisiert, was

\footnotetext{
${ }^{39}$ Vgl. Zofia Stefanowska: Świat owadzi w czwartej części Dziadów. In: Dies.: Próba zdrowego rozuти..., op.cit., S. 83 u. 87 ff.
} 
den leitmotivischen Charakter des Begriffes droga etwas abschwächt. Schamschula findet für kraj daleki nur eine umschreibende Entsprechung (bald schon ruft's mich von hier weit!). Die Übersetzung von G. Hagenau gleich gehe ich wieder weit fort ist umgangssprachlich, die immer deutlicher und unheimlicher werdenden Anspielungen auf die jenseitige Provenienz Gustavs kommen hier nicht zum Ausdruck.

Eine unter Interpreten der Dziady umstrittene Stelle ist das Bekenntnis, das häufig - aber keineswegs zwingend - als Hinweis auf den vollzogenen Selbstmord Gustavs ausgelegt wird:

Wtem anioł śmierci wywiódł z rajskiego ogrodu! (AM 80)

Lipiner: Und da geschah's - da hat der Todesengel / Mich aus dem Paradies geführt! (SL 89) Schamschula: Hat der Todesengel aus dem Eden mich vertrieben! (WS 161)

(Bei G. Hagenau wird die Stelle ausgelassen)

Damit endet die Erzählung Gustavs über das Hochzeitsfest seiner Geliebten, das er, von Verzweiflung, Eifersucht und Rachedurst geplagt, von Ferne beobachtete. Hier stehen dem Leser nur zwei Übersetzungen zur Verfügung. Lipiner versteht Gustavs Worte als Hinweis auf Selbstmord: Das bei Mickiewicz nicht vorhandene und da geschah's bezieht sich auf eine vollzogene Tat, die mit hoher Wahrscheinlichkeit den Tod aus eigener Hand bedeutet. Somit legt Lipiner dem Leser nahe, die Gestalt des Protagonisten als Gespenst eines Toten zu deuten. Die Version Schamschulas lässt hier - so wie das Original - unterschiedliche Interpretationen zu, wobei Anklänge an die Bibel lexikalisch verdeutlicht werden (die Vertreibung aus dem Garten Eden).

Unmittelbar vor seinem folgenlosen Selbstmord durch Erdolchung beklagt Gustav den einsamen Tod eines Eremiten. In seiner Klage gipfelt die dramatische Spannung und zugleich die düstere, beklemmende Mehrdeutigkeit des Textes. Wir wissen nicht, ob der Held seinen künftigen Tod als Einsiedler meint, oder ob er bereits freiwillig aus dem Leben geschieden ist. Gustavs einziger Wunsch wäre, dass die Geliebte bloß einen Tag um ihn trauert. Bald aber werden seine Emotionen von gekränktem Stolz übertönt sowie von einem vergeblichen Versuch, die Gestalt des Mädchens zu vergessen:

\section{(z dzikq ironia)}

Stój, stój, żałośne pisklę!... precz, wrzasku niewieści!

Będęż, jak dziecko szczęścia, umierając szlochał?

Wszystko mi, wszystko niebiosa wydarły,

Lecz reszty dumy nie moga odebrać!

Żywy, o nic przed nikim nie umiałem żebrać,

Żebrać litości nie będę umarły!

( $z$ determinacja)

Rób, co chcesz, jesteś woli swojej panią,

Zapomnij!... ja zapomnę!

(pomieszany) 
wszak już zapomniałem?

(zamyślony)

Jej rysy... coraz ciemniej... tak, już się zatarły!

Już ogarniony wieczności otchłanią

Doczesnym pogardzam szałem...

(pauza)

Ach, wzdycham! czegoż wzdycham? Ha, westchnąłem za nią

Nie! nie mogę zapomnieć o niej i umarły.

Wszakże ją widzę, wszak tu, o, tu stoi!

Płacze nade mną... jaka łezka szczera!

(z żalem)

Płacz, moja luba, twój Gustaw umiera! (AM 85 f.)

Lipiner:

(Mit wilder Ironie.)

Halt, halt, Piepmätzchen! Schweig', du Weiberjammer!

Was? Schluchzend stürb' ich, wie ein Kind des Glücks?

Wenn mir der Himmel Alles, Alles nahm:

Den Rest von Stolz doch nicht! Mocht' ich im Leben

Niemals um irgend was zu betteln mich versteh'n,

Werd'ich nun nach dem Tod nicht Mitleid betteln geh'n! -

Thu', was du willst, bist deines Willens Herrin:

Vergiß! auch ich vergesse - (verwirrt) Hab' ich schon vergessen!

Sieh', ihre Züge - immer dunkler, - schon

Verwischt, vom Schlund der Ewigkeit verschlungen;

Wahnsinn der Zeitlichkeit, was bist du mir?

(Pause.)

Ich seufze - warum seufz' ich? Ha, um sie;

Der Tod, der Tod auch konnt' es nicht verlöschen, -

Ich seh' sie: ja - hier, hier! Da steht sie - dort!

Weint über mich - o echte Herzensthräne!

(Wehmüthig:) Weine, mein holdes Lieb - dein Gustav stirbt! (SL 93 f.)

Schamschula:

(mit wilder Ironie)

Fort, ach, weibisches Gezeter! Schweig, du Küken!

Wie ein Glückskind etwa, seufzend, stürbe ich?

Alles, alles hat der Himmel mir genommen,

Doch den Rest von Stolz geb ich nicht hin,

Niemals bettle ich, wo ich am Leben bin,

Werde nach dem Tod nicht Mitleid betteln kommen.

(mit Entschiedenheit)

Also zu! denn du befiehlst dem eignen Willen,

Frag „vergiß!“ ‘... und ich vergesse!

(verstört)

(nachdenklich)

Hab dein Bild verjagt!

Ihre Züge... dunkel schon - und schon verschwommen,

Seh den Schlund der Ewigkeiten mich verhüllen,

Hab dem Wahn der Zeitlichkeit entsagt...

(Pause) 
Ach, ich seufze! und weshalb? ich seufz' um ihretwillen,

Nein! Vergessen? auch den Toten muß es überkommen.

Nein! ich seh sie, sehe sie von Angesicht!

Ehrlich ist die Träne, die sie um mich weint!

(mit Kummer)

Weine, Liebe, sieh ihn sterben, Gustav, deinen Freund! (WS 171)

(Bei G. Hagenau wird die Stelle ausgelassen)

An dieser Stelle konkurrieren die ,diesseitige” und die ,jenseitige” Version des Protagonisten am stärksten miteinander. Gustav bekennt sich aber weder zum „Diesseits“ noch zum „Jenseits“, weicht gewissermaßen einer eindeutigen Erklärung aus, indem er im Original die Opposition żywy - umarty (lebendig - tot) ausspielt und die Ambivalenz der grammatischen Tempora ausnutzt. Während das polnische Präteritum in Żywy, o nic przed nikim nie umiatem żebrać sich auf die Vergangenheit bezieht, kann das Futur im Satz Żebrać litości nie będę umarly entweder die Absicht des Sprechenden auf die Zukunft projizieren (wenn wir annehmen, dass Gustav noch lebt), oder aber seinen jetzigen Zustand ausdrücken, den der Held als Analogie zur Vergangenheit sieht (dann würde es bedeuten, dass er schon gestorben ist). Die scheinbare Eindeutigkeit der Feststellung nie mogę zapomnieć o niej $i$ umarly wird gleich wieder aufgehoben durch die Ankündigung des Todes in der Aufforderung an die Geliebte: płacz, moja luba, twój Gustaw umiera! - d.h. dass er im Sterben liegt. Die auf den Sprechenden bezogene Metapher Już ogarniony wieczności otchtaniq / Doczesnym pogardzam szatem drückt lediglich sein Schweben zwischen Jenseits und Diesseits aus, ohne zur Entscheidung in der grundlegenden ontologischen Frage etwas beizutragen. Vielmehr schlägt sich in der sprachlichen Struktur dieser Worte das Weltbild von Dziady nieder: Die Grenzen zwischen Gegenwart, Vergangenheit und Zukunft sind relativ und verschwommen, die Zeit bildet eine Ganzheit.

Kein Übersetzer weiß dieses faszinierende sprachlich-philosophische Spiel wiederzugeben, auch wenn es grundsätzlich auf der Ebene der polnischen Grammatik realisiert wird und im Deutschen durchaus nachzubilden wäre. Sowohl Lipiner als auch Schamschula erliegen hier der Versuchung, sich in der Übersetzung für die „diesseitige“ oder die ,jenseitige“ Sinngebung der Hauptgestalt auszusprechen. In der Nachdichtung von Lipiner erkennt man die Stimme eines Toten - allein wegen des eingefügten Adverbs nun, das die Aussage ihrer gesamten Relativität beraubt: Werd' ich nun nach dem Tod nicht Mitleid betteln geh'n! Das Präteritum in Der Tod, der Tod auch konnt' es nicht verlöschen legt nahe, dass der Tod des Protagonisten schon hinter ihm liegt. Die Metapher vom Schlund der Ewigkeit verschlungen bezieht sich nicht - wie bei Mickiewicz - auf den Sprechenden, sondern auf seine Geliebte, deren Züge er aus seiner Erinnerung verdrängen will. Diese scheinbar geringfügigen Sinnverschiebungen bewirken, dass der Gustav von Lipiner als ein Toter zu interpretieren ist. 
Dagegen spricht in der Fassung von Schamschula ein lebendiger Mensch: Niemals bettle ich, wo ich am Leben bin. Das von Mickiewicz ausgesparte Präsens verankert den Protagonisten, der im Originaltext zwischen relativ gewordener Vergangenheit und Zukunft schwebt, fest in der Gegenwart, in dem hic et nunc, und definiert ihn als lebendiges Wesen. Gustavs Bekenntnis in der polnischen Vorlage, er könne auch als Toter seine Geliebte nicht vergessen (nie mogę zapomnieć o niej $i$ umarly), wird ersetzt durch das unklare und wohl auf dem Missverstehen des Originals beruhende: Vergessen? auch den Toten muß es überkommen!, womit der Sprechende nicht unbedingt sich selbst meint.

G. Hagenau lässt den gesamten angeführten Abschnitt aus und verschiebt damit die Akzente im Gesamttext. Es fehlt einer der Schwerpunkte der Polemik zwischen den beiden Gesprächspartnern und zugleich des psychologischen Experimentes, das Gustav an der Person des Priesters durchführt. Die Aufmerksamkeit des Lesers konzentriert sich auf die - zweifellos besonders bühnenwirksame - Szene der Erdolchung, die der Erzählung des Helden über seine enttäuschte Liebe folgt. Ohne die vorangehenden Schwankungen seiner Gemütslage, ohne das im Original so beklemmende Oszillieren zwischen „Jenseits“ und „Diesseits“ entbehrt der Selbstmord Gustavs einer tieferen psychologischen Motivation und wird zu einem genauso traurigen wie voraussehbaren Ende einer banalen Liebesgeschichte.

Erst als der Glaube des Priesters an den gesunden Menschenverstand erschüttert wird und sein verdrängter Hang zum Aberglauben ans Tageslicht kommt, enthüllt Gustav den Grund seines nächtlichen Besuches bei dem ehemaligen Lehrer:

Słuchaj, jakie mię na świat zamiary przywiodły. (AM 89)

Lipiner: Hör', was mich auf die Erde hergeführt: (...) (SL 97)

G. Hagenau: Hör mich an, was mich zu dir geführt hat. (GH 210)

Schamschula: Hör, weshalb aus fernem Reich ich bei dir eingetreten: (...) (WS 177)

Bei Mickiewicz gewinnt hier erneut die ,jenseitige Version“ des Protagonisten die Oberhand: Gustav kehrt „auf die Welt“ zurück, mit der Bitte an seinen Gastgeber, das beinahe ausgerottete, heidnische Ritual der dziady, der Totenbeschwörung, wieder begehen zu lassen. Für diese Version (auf die Erde) entscheidet sich auch Lipiner. Schamschula nennt dagegen nicht das Ziel, sondern die Herkunft des Protagonisten: fernes Reich - was mit jenem Reich korrespondiert, das Gustav am Anfang seines Besuches erwähnt. Die Übersetzung von G. Hagenau gibt uns keine Grundlage anzunehmen, dass Gustav ein Abgesandter der Verstorbenen ist, in deren Namen er spricht, Ihr Text ist umgangssprachlich und neutral im Hinblick auf die Markierung des ungewöhnlichen Wesens des Protagonisten.

Die Analyse der ausgewählten Stellen, die den ontologischen Status des Helden andeuten, lässt sich nun wie folgt zusammenfassen:

Die Frage, ob Gustav dem Jenseits oder dem Diesseits angehört, wird im Originaltext absichtlich nicht entschieden. Lipiner und Schamschula versuchen, die 
ontologische Ambivalenz des Protagonisten, die in dem Weltbild von Dziady eine bestimmte Funktion erfüllt, wiederzugeben - bis zu der Stelle, wo Lipiner seinen Gustav doch als Toten interpretiert, Schamschula hingegen als lebendigen Menschen. Zudem fallen in der Nachdichtung von Schamschula relativ häufige religiöse Konnotationen auf, die im Ausgangstext keine Entsprechungen haben.

Die Fassung von G. Hagenau folgt der Originalvorlage auf der lexikalischen Ebene, zugleich aber fallen bedeutende Textpartien aus, so dass es für den Leser unmöglich ist, die zunehmende Verselbständigung der Metapher aus dem semantischen Feld „Leben - Tod“ und die aufkommenden Zweifel an dem ontologischen Status des Helden nachzuvollziehen. Die Handlung zielt daraufhin, Gustav eindeutig als einen Wiedergänger zu entpuppen. Eine negative Rolle spielt dabei die von G. Hagenau direkt dem Teil IV vorangestellte Ballade Upiór bzw. deren wenige Strophen, die - der metaphysischen Ebene beraubt und zu einer Anekdote verflacht - den Protagonisten als Gespenst vorausbestimmen und sein „ontologisches Geheimnis" zerstören. In den Nachdichtungen von Lipiner und Schamschula fungiert die Ballade - so wie in der Originalfassung - als selbständiges, mit Teil IV nur lose verknüpftes Element.

\subsection{Das Moment der Erinnerung und der persönlichen Vergangenheit}

Die Erinnerung als Bestandteil der angesprochenen Motivkette „Leben vs. Tod“ und „Erinnern vs. Vergessen“ ist in Teil IV von Dziady ein derart dominantes Leitmotiv, dass man den Text begründeterweise als „Beschwörung der Erinnerung gegen das Vergessen“40 lesen kann. R. Fieguth sieht in dem Grundgedanken des „Erinnerungszwanges“, der in dem Begriffsfeld „Erinnerung, Gedächtnis, NichtVergessen-Wollen" realisiert wird, das oberste Kompositionsprinzip der gesamten „Gustav-Dichtung“. Das Erinnerungsmotiv hat aber auch - durch die Person Gustavs - im Weltbild von Dziady eine bedeutende Rolle zu erfüllen.

Das geistige Leben des Helden spielt sich ausschließlich auf der Ebene der Erinnerungen ab. Zugleich muss der Protagonist um sein Recht auf Erinnerung und eigene Vergangenheit, das ihm der Priester durch seine sachlich-nüchternen Kommentare immer wieder entzieht, ständig ringen - und das mit gutem Grund: Das Erinnerungsvermögen und die eigene Vorgeschichte konstituieren Gustavs Identität. Die individuelle Biographie, die in der Erinnerung wieder belebte Vergangenheit (welche die Zeit als organische Ganzheit erscheinen lässt) verleihen dem Protagonisten seinen einzigartigen menschlichen Charakter und psychologische Glaubwürdigkeit. Ansonsten könnte man seine Erlebnisse begründeterweise als eine übliche, nach der Konvention der Empfindsamkeit gestaltete Liebesgeschichte lesen, mit allen literarischen Requisiten (Zypressenblatt, Haarlocke u.Ä.) und einem

\footnotetext{
${ }^{40}$ R. Fieguth, op.cit., S. 281.
} 
Übermaß an theatralischer Staffage. ${ }^{41}$ Das, was von der Darstellung einer schematischen Dreiecksbeziehung abweicht, rührt ausschließlich von Gustavs Erinnerungen her. Indem der Protagonist so obsessiv auf die Vergangenheit fixiert ist, vermittelt er eine der Grundideen von Dziady: Der Besitz eigener, einzigartiger Erinnerungen ist die Voraussetzung dafür, ein Individuum zu bleiben und volle Menschlichkeit zu erlangen.

Dieser Gedanke gilt nicht nur dem Einzelmenschen, sondern erstreckt sich auf die ganze Gemeinschaft. Gustav kann und will seine Vergangenheit nicht vergessen, er will aber zugleich selbst nicht vergessen werden. In der Pfarrstube spricht er im Namen aller Verstorbenen, und sein Anliegen, die dziady - das „Fest der Erinnerungen bzw. des Gedenkens" (święto pamiątek) - wieder feiern zu dürfen, bedeutet, den Toten ihr gutes Recht auf das Nicht-Vergessen-Werden einzuräumen; denn allein die Erinnerung, die sich im Gedenken und im Gebet der Lebendigen ausdrückt, lässt die Vorfahren weiter leben, schafft ein geistiges Band zwischen Diesund Jenseits und liegt letztendlich der Gemeinschaft der Heiligen zu Grunde. Die „öffentliche Erinnerung“, die sich mit dem Motiv der persönlichen Erinnerung kreuzt, wird somit zu einer religiös begründeten sozialen Pflicht erhoben.

Wir wollen hier einige Stellen verfolgen, die das Bedeutungsfeld „Erinnerung, Gedächtnis“ aktivieren. Zu den polnischen Schlüsselwörtern, die dieses Feld konstituieren, gehören die Verben pamiętać (sich erinnern), wspominać (gedenken, an etwas zurückdenken; jemanden / etwas im Gespräch beiläufig erwähnen), przypominać (jemanden an etwas erinnern, mahnen; sich etwas in Erinnerung rufen) sowie die Substantive pamięć (Erinnerungsvermögen, Gedächtnis), pamiqtka (Erinnerungsstück, Andenken). ${ }^{42}$ Die meisten davon hängen mit Gustavs Erinnerung an das vergangene Glück und den Abschied von der Geliebten zusammen, an den ihn einer der „selbständig wuchernden Erinnerungsfetische“43 - ein Zypressenzweig erinnert:

Jodła? a, Ksiądz uczony! o głowo ty, głowo! Przypatrz się lepiej, poznaj gałąz cyprysową; To pamiątki rozstania, mego losu godła. (...) Jej ręką ułamana gałąź cyprysowa Zawsze mi przypomina ostatnie 'bądź zdrowa!' (AM 51)
Schamschula:

Tanne? Nein, des Abschieds Zeichen, Sinnbild dessen,

Welches Los ich trag, ist eine Rute von $\mathrm{Zy}$ pressen!

Pfarrer, o gelehrtes Haupt! wie bist du weise! (...)

Ein Zypressenreis, von ihrer Hand gebrochen, Gab sie mir, da sie das letzte Lebewohl gesprochen, (...) (WS 109)

G.Hagenau:

Tannenast? Oh, der Pfarrer ist gelehrt!

Lipiner:

Tanne?

\footnotetext{
${ }^{41}$ Vgl. Z. Stefanowska, op.cit., S. 83 ff.

${ }^{42}$ Vgl. die Zusammenstellung bei R. Fieguth, op.cit., S. 282-285.

${ }^{43}$ R. Fieguth, op.cit., S. 279.
} 
Ach, ein gelehrter Priester! Weises Haupt! Sieh näher zu, 's ist ein Cypressenzweig, Denkbild des Scheidens, Sinnbild meines Schicksals! (...)

Cypressenzweig! von ihrer Hand gebrochen,

Du mahnst mich stets an's letzte Lebewohl!

(SL 62 f.)

Obraz tego rozstania dotąd w myśli stoi.

Pamiętam, śród jesieni... przy wieczornym chłodzie:

Jutro miałem wyjechać... błądzę po ogrodzie! (...)

Noc była najpiękniejsza! Pamiętam dziś jeszcze: (...) (AM 53)

Lipiner:

Dies Scheiden! Noch, - noch steht das Bild vor Bei G.Hagenau wird die Stelle ausgelassen mir:

Herbst war's, ein kühler Abend; nächsten

Tages

Sollt' ich hinweg, Ich schweife durch den

Garten, - (..)

Es war die schönste Nacht - noch heut' gedenk' ich's - (...) (SL 64f.)
Sieh mal näher hin! Das ist ein Zypressenzweig!

Zum Zeichen der Erinnerung an unseren Abschied. (...)

Dieser von ihrer Hand gebrochene Zypressenzweig

Erinnert mich stets an unser letztes „Lebewohl“! (GH 199)

Schamschula:

Noch steht vor mir dieses Abschieds Bild,

Herbst war's, Abendkühle: weiß die Zeit noch und den Ort,

Schweift ich durch den Garten... in der Frühe mußt' ich fort! (...)

Selig schöne Nacht! ich seh sie vor mir jetzt, (...) (WS 113)

Die Verben des Erinnerns, die Gustav in seinem Monolog ausspricht, lauten: przypominać (erste zitierte Textpassage) und pamiętać (zweite Passage). Der Zypressenzweig erinnert (przypomina) Gustav an das letzte Lebewohl; Gustav erinnert sich (pamiętam) an den herbstlichen Garten - die Szenerie des Abschieds. „Das Signalwort" pamiętam, im zweiten Textbeispiel im Original sogar verdoppelt, wird gleichsam zu einer magischen Formel, mit der Gustav seine Vergangenheit heraufbeschwört. Dort, wo der „Einsiedler” an vergangene Ereignisse aus seinem Leben zurückdenkt und diesen Erinnerungsvorgang auch verbalisiert, rückt seine literarische Provenienz in den Hintergrund, seine ansonsten so auffallende theatralische Maske wird aufgehoben. Es spricht hier kein stilisierter ,polnischer Werther“, sondern ein lebendiger, innerlich gebrochener und in seiner Natürlichkeit ergreifender Mensch. Mit seinen verwirrten Gedankengängen, den Schwankungen seiner Gemütslage - von Liebe und Verzweiflung über Selbstironie bis hin zum Hass auf die untreue Geliebte - korrespondieren die beiden vorgenannten Verben przypominać und pamiętać, die im Polnischen (genauso wie das deutsche erinnern) für einen spontanen, assoziativen, subjektbezogenen Erinnerungsprozess stehen (auch das mehrdeutige przypominać, das jemanden an etwas erinnern genauso wie sich etwas in Erinnerung rufen bedeutet). 
Lipiner verwendet an den angeführten Stellen die Verben mahnen (für przypominać) und gedenken (für pamiętać), wobei das letztere im deutschen Text nur einmal vorkommt, daher kaum auffällt und den Charakter eines "Signalwortes“ nicht besitzt. Mahnen und gedenken entsprechen zwar semantisch den Zeitwörtern des Originals, gehören jedoch einer höheren stilistischen Ebene an als die polnischen pamiętać und przypominać und scheinen deren konnotativen Wert sowie den Beitrag zur Gestaltung von Gustavs Gesamtbild nicht wiederzugeben. Die beiden deutschen Verben bedeuten keinen unwillkürlichen, impulsiven mentalen Vorgang, sondern gleichsam eine kulturell bzw. sozial bedingte, erzwungene Erinnerung. ${ }^{44}$ Gedenken legt das Erinnern an ein denkwürdiges Ereignis nahe, in das der Sprechende nicht unbedingt selbst involviert war, während Gustavs Bekenntnis $p a$ miętam stark subjektbezogen ist, da er den Abschied doch selbst erlebte; die Erinnerung daran stellt sich unabhängig von seinem Willen ein. Lipiners Wortwahl ist mit einer der Gründe, warum sein Gustav einen so gehobenen, literarischen und viel weniger spontanen Eindruck erweckt als in der Übersetzungsvorlage.

G. Hagenau scheint die Rolle des Leitmotivs der Erinnerung auf der lexikalischen Ebene richtig zu erfassen, indem sie das Verb przypominać nicht etwa als mahnen, sondern als erinnern übersetzt. Die Erinnerung Gustavs an die Schauplätze seiner Liebesgeschichte wird indes ausgelassen. Auf die Bedeutung dieser und anderer Leerstellen kommen wir noch zu sprechen.

Die Nachdichtung von Schamschula enthält in den angeführten Passagen überhaupt keinen lexikalischen Hinweis darauf, dass Gustavs Erinnerungsvermögen gefordert wird. Im ersten Zitat kommt kein einziges Wort aus dem Bedeutungsfeld Erinnern vor. Ein Zypressenreis, von ihrer Hand gebrochen, / Gab sie mir, da sie das letzte Lebewohl gesprochen kommt einem Bericht gleich und nicht - wie im Original - einer Reflexion. Anstatt der Erinnerung an den Abschied bekundet Gustav in der Version von Schamschula seinen Wissensstand: ich weiß die Zeit noch und den Ort, bzw. visualisiert er das Erinnerte: ich seh sie [d.h. die Nacht] vor mir jetzt. Gustav ist hier ein ausgesprochener Augenmensch, er macht einen weniger nachdenklichen, dafür aber sachlicheren Eindruck als der Protagonist von Mickiewicz. Übrigens bestätigt sich dieser Eindruck an einer weiteren Stelle, wo Gustav für die vielen Erinnerungsstücke im Haus der Priesters und in seiner ehemaligen Schule schwärmt:

Ile znowu pamiątek w twoim domku, w szkole! (AM 75)

Lipiner: Und was sich an dein Haus knüpft, an die Schule! - (SL 84)

Schamschula: Seh ich euch hier wieder, Bilder aus der Jugendzeit? (WS 153)

(Bei G. Hagenau wird die Stelle ausgelassen)

\footnotetext{
${ }^{44}$ Diese „kulturelle Markierung” kommt besonders in Wortbildungen wie etwa Mahnmal oder Gedenkstätte zum Tragen.
} 
Das Leitmotiv der Erinnerung wird hier in keiner Übersetzung aktiviert. $P a$ miqtki (Erinnerungsstücke) werden bei Schamschula zu Bildern, ein mentaler Vorgang wird also auf die Ebene der Sinne projiziert. Der Gustav dieser Nachdichtung sieht, denkt und berichtet, erinnert sich aber nicht.

Pamiatka (Erinnerungsstück) ist ebenfalls ein häufiges Wort aus dem Bedeutungsfeld „Erinnerung“. In der ersten angeführten Passage erwähnt Gustav pamiqtki rozstania (Erinnerungsstücke des Abschieds) - Gegenstände, die ihn an die Kontinuität seines Schicksals erinnern und seine Vergangenheit nicht vergessen lassen. Dieser gedankliche Gehalt ist nur der Übersetzung von G. Hagenau zu entnehmen: Zeichen der Erinnerung an unseren Abschied. Weder das Denkbild des Scheidens bei Lipiner noch des Abschieds Zeichen bei Schamschula haben diese Aussagekraft und die Macht, den Helden gedanklich in vergangene Zeiten zu versetzen.

Andererseits haben alle drei Übersetzer die Schlüsselrolle des Wortes pamiqtka häufig auch richtig erkannt. Gustav irrt durch kraje pamiqutek (Lande der Erinnerungen - AM 74) - was man verstehen kann entweder als reale Wanderung durch die Gegend, in der er aufwuchs und seine Liebe erlebte, oder auch metaphorisch: als mentale Wanderung durch seine Erinnerungen. Diesen Gehalt besitzen auch die deutschen Fassungen von Lipiner: diese Lande der Erinnerungen (SL 82) und von G.Hagenau: das Land meiner Erinnerungen (GH 207), wogegen die Interpretation von Schamschula der Erinn'rung Wanderschaft (WS 149) eher für eine „geistige Wanderschaft" spricht.

Ein wichtiger „Erinnerungsfetisch” ist ein Blättchen, das Gustav im Garten findet und darin dasjenige erkennt, das er einst mit der Geliebten geteilt hatte und dessen eine Hälfte er immer bei sich trägt. Das von dem Mädchen (absichtlich?) verlorene Blatt ruft lebhafte Erinnerungen hervor:

Tenże sam listek, listka mojego połowa, (dobywa listek)

Który mi przypomina ostatnie 'bądź zdrowa!'

To mój dawny przyjaciel, czulem go powitał,

Długo z nim rozmawiałem i o wszystkom pytał: (...)

Czy na moje wspomnienie rumieni się skromnie?

Czy sama czasem niechcąc nie wspomina o mnie?... (...)

Więc (pokazujac listek) ostatni przeszłości odrzuciła szczatek!

Więc już jej moich nosić nie wolno pamiątek! (AM $78 \mathrm{f.}$ )
Schamschula:

Eben jenes Blatt, - des andre Hälfte trage ich.

(holt das Blatt hervor)

An das letzte Lebewohl gemahnt es mich!

Stürmisch hab ich ihn begrüßt, den Freund aus alten Zeiten,

Lange hab ich ihn befragt nach allen Einzel-

heiten: (...)

Sahst du sie erröten, da man meinen Namen spricht,

Hat sie unwillkürlich mein gedacht? du weißt es nicht?

Nun, (zeigt das Blättchen)

sie hat den letzten Rest des Einst von sich geschlagen!

Also darf auch ich den meinen nicht mehr bei mir tragen! (WS 157, 159) 
Lipiner:

Dasselbe Blättchen! meines Blättchens Hälfte, Das stets mich mahnt an's letzte Lebewohl (Er langt es hervor.)

Mein alter Freund! Recht herzlich grüßt' ich ihn,

Sprach lang mit ihm, fragt' ihn nach Allem aus: (...)

Ob sie bei meinem Namen leis erröthet -

$\mathrm{Ob}$ sie nicht unwillkürlich mein gedenkt? (...)

So hat sie denn das letzte Stück Vergangenheit

Von sich geworfen! darf mein Angedenken

Nicht länger tragen! (SL 86 ff.)

\section{G.Hagenau:}

(die ersten Zeilen wurden ausgelassen)

[Gustav] (Zeigt ein Blatt)

Sie hat auch dies letzte Zeichen der Erinnerung

fortgeworfen,

Also darf sie nicht einmal mehr dieses Andenken tragen! (GH 207)

Lipiner gibt pamiatka sinngemäß, wenn auch stilistisch gehoben als Angedenken wieder. Bei Schamschula gibt es dafür keine Entsprechung (bedeutungsmäßig weichen die beiden letzten Zeilen von der Originalvorlage ab). G. Hagenau lässt das so viele Erinnerungen aktivierende „Gespräch” Gustavs mit dem wiedergefundenen Blatt aus und scheint die Leerstelle durch die bekräftigende Verdoppelung des Erinnerungsmotivs kompensieren zu wollen: anstatt przeszłości szczatek (der Rest der Vergangenheit) lesen wir dies letzte Zeichen der Erinnerung, und für pamiqtka steht hier Andenken.

In dem angeführten Abschnitt wird auch die Mehrdeutigkeit des Wortes wspomnienie (von: wspominać - erinnern, gedenken, aber auch: [beiläufig] erwähnen) ausgespielt. Der Doppelsinn wird in den Übersetzungen von Lipiner und Schamschula nur teilweise nachgebildet: $O b$ sie bei meinem Namen leis erröthet -/ $O b$ sie nicht unwillkürlich mein gedenkt? (Lipiner), Sahst du sie erröten, da man meinen Namen spricht, / Hat sie unwillkürlich mein gedacht? (Schamschula). Übrigens kann man die Frage stellen, ob die Formulierung unwillkürlich gedenken nicht in sich widersprüchlich ist. Mit dem Verb przypominać verfahren die beiden Übersetzer wie in der ersten angeführten Passage und setzen dafür mahnen (Lipiner) bzw. gemahnen (Schamschula) ein - eine weitere Bestätigung, dass Gustavs Erinnerungen in den deutschen Texten sich nicht spontan, sondern infolge eines kulturbzw. sozial bedingten mentalen Prozesses einstellen.

Die folgenden Bemerkungen gelten nun der Version von G. Hagenau. In den Textpassagen, die nicht den vorgenommenen Kürzungen zum Opfer fielen, fällt die konsequente Verwendung der Wörter erinnern, Erinnerungen für das polnische pamiętać, przypominać, pamiqutki auf. Die Übersetzerin behält den Charakter des Erinnerungsmotivs bei, allerdings nur auf der Ebene der Lexik. Demgegenüber sind beinahe alle längeren Monologe, in denen Gustav seine Erinnerungen aufleben lässt, weggefallen. 
$\mathrm{Zu}$ den dadurch entstandenen Leerstellen gehören sämtliche in die Dichtung eingeflochtenen „Fremdtexte“. ${ }^{45}$ Einer davon ist ein ironisches Loblied auf ein Mädchen, das sich an ihren (verstorbenen?) Geliebten zuerst jede Stunde, dann jeden Tag, jede Woche und schließlich nur noch jedes Jahr erinnert. Bei Mickiewicz werden in dem Lied die Vergänglichkeit der menschlichen Erinnerung und die vernichtende Macht des Vergessens angesprochen - ein Grundgedanke von Dziady, der in der Übersetzung von G. Hagenau nur einen schwachen Nachklang findet.

Eine weitere Gruppe der Leerstellen sind verbalisierte Erinnerungen des Helden, die sich an die Person der Geliebten knüpfen, aber auch an seine Kindheit und die Schuljahre. Unter den ausgelassenen Szenen ist Gustavs Erinnerung an den Besuch in dem zugrunde gerichteten Elternhaus besonders ergreifend. Selbst von seinen Angehörigen vergessen, kehrt Gustav nach Jahren in seine Heimat zurück und muss erleben, wie Diebe das Haus plündern - burzac do reszty świętej przeszłości ostatki (AM 75) (Zertrümmernd noch die letzten heil'gen Trümmer - SL 83, So verwüstend heil'ge Reste der Vergangenheit - WS 151). Dem Bild der „Zertrümmerung der Vergangenheit" kommt ein symbolischer Wert zu: Zusammen mit seiner einzigartigen, vom Elternhaus verkörperten persönlichen Lebensgeschichte verliert Gustav die psychische Grundlage seiner Existenz und wird als Mensch vernichtet.

G. Hagenaus Bearbeitung von Teil IV der Dziady richtet sich nach dem Prinzip, Gustavs Erinnerungen und damit das Individuelle seiner poetischen Biographie auszublenden oder schlichtweg zu streichen (dieses Motiv wird auch aus der bereits erwähnten Ballade Upiór entfernt). Eine konsequente Beibehaltung des Erinnerungsmotivs auf der lexikalischen Ebene kann diesen Verlust alleine nicht aufwiegen. Was übrig bleibt, ist eine banale Liebesgeschichte, und der Protagonist wird gleichsam ein Mann ohne Vergangenheit, ein typischer, empfindsamer Liebhaber. Diesen Befund könnte man sogar als „Ironie der Übersetzung“ bezeichnen: die deutsche Nachdichtung beraubt den Helden von Mickiewicz gerade derjenigen Werte, um die er im Original ringt.

$\mathrm{Zu}$ den Übertragungen von Lipiner und Schamschula bleibt Folgendes festzuhalten. Beide Übersetzer haben den leitmotivischen Charakter der Schlüsselwörter aus dem Begriffsfeld Erinnerung teilweise übersehen (wobei dies im Text von Schamschula häufiger der Fall ist), ansonsten aber das Erinnerungsmotiv auf eine andere Art und Weise realisiert, indem sie ein unterschiedliches Raster von Schlüsselbegriffen auf ihre Texte auflegen. Die polnischen Verben: pamiętać, wspominać, przypominać erscheinen in den deutschen Fassungen meistens als gedenken und (ge)mahnen - Zeitwörter eines „erzwungenen“ Erinnerns. Von einer solchen, als gemeinschaftliche Pflicht verstandenen Erinnerung spricht Gustav in der Original-

${ }^{45}$ U.a. Nachdichtungen aus Schiller (eine freie Bearbeitung einzelner Strophen aus den Gedichten Amalie und Der Jüngling am Bache), Selbstzitate (aus den Balladen und Romanzen und der Ode an die Jugend) sowie stilisierte Volkslieder. 
vorlage nur dort, wo er die dziady - das „Fest des Gedenkens” zur sozialen Notwendigkeit, zur Voraussetzung für die Kontinuität von Diesseits und Jenseits erhebt. Es ist der einzige Kontext, in den die Wörter gedenken und (ge)mahnen hineinpassen. Das Persönliche, Spontane und Impulsive an Gustavs Erinnerungen weicht in den Nachdichtungen von Lipiner und Schamschula einer ausgesprochen sozial bzw. kulturell bedingten Reflexion, die der gesellschaftlich-religiösen Bedeutung der Ahnenfeier entspricht.

\section{Schlussbemerkung: das katholische Weltbild des dramatischen Fragments Dziady als mögliche Rezeptions- und Übersetzungsblockade}

Zum Schluss seien noch zwei Zitate angeführt: eine Stelle aus der Polemik zwischen Gustav und dem Priester, an der Gustav sein Glaubensbekenntnis ablegt, und ein Absatz aus dem Vorwort Mickiewiczs zu Teil II, in dem der Dichter die Geschichte und das Wesen der Ahnenfeier skizziert. Das religiöse Weltbild des dramatischen Fragments wird in beiden Fällen auf den Punkt gebracht und muss nicht anhand der im Vorangegangenen analysierten Motivketten, also gewissermaßen „Zwischen den Zeilen” abgelesen werden:

GUSTAW: No, przyznaj się szczerze,

Czy wierzysz w piekło, w czyściec?...

KSIĄDZ: Ja we wszystko wierzę,

Cokolwiek w Piśmie świętym Chrystus nam ogłasza

I w co zaleca wierzyć Kościół, matka nasza.

GUSTAW: I w co twoje pobożne wierzyły pradziady?

Ach! najpiękniejsze święto, bo święto pamiątek,

Za cóż zniosłeś dotychczas obchodzone Dziady? (AM 90)

Lipiner:

GUSTAV. Aufrichtig - sag' mir:

Glaubst du an Höll' und Fegefeuer?

PFARRER. Alles

Glaub' ich, was Christus sagt und was zu glauben

Die heilige Mutter Kirche uns empfiehlt.

GUSTAV. Und auch was deine frommen Ahnen glaubten?

Die schönste Feier, die Erinn'rungsfeier,

Bis heute stets begangen, - sag', warum

Hast du sie abgeschafft: die Todtenfeier? (SL 97)

Schamschula:

GUSTAV: Sei ehrlich! glaubst du, frag ich dich,

An die Hölle, Fegefeuer?

PRIESTER: An das alles glaube ich,

Was uns Jesus Christ im Testament verkündet

Und die heil'ge Mutter Kirche uns zu glauben bindet. 
GUSTAV: Auch, was deine Ahnen fromm geglaubt von Alters her?

Das Erinn'rungsfest, das schönste, einst begangen,

Warum feierst du das Totenfest nicht mehr? (WS 177)

Hagenau:

GUSTAV: Gestehe nur, glaubst du an die Hölle und das Fegefeuer?...

PFARRER: Ich glaube an alles, was uns Christus in der Bibel verkündet

Und an was uns die Kirche, unsere Mutter, zu glauben, befiehlt.

GUSTAV: Und woran haben deine frommen Vorfahren geglaubt?

Ach, das schönste Fest, denn ein Fest der Erinnerungen,

Warum hast du die Totenfeier, die Dziady aufgehoben? (GH 210)

Dzi a y nasze mają to szczególnie, iż obrzędy pogańskie pomieszane są z wyobrażeniami religii chrześcijańskiej, zwłaszcza iż dzień zaduszny przypada około czasu tej uroczystości. Pospólstwo rozumie, iż potrawami, napojem i śpiewami przynosi ulgę duszom czyscowym. (AM 11)

Unsere „Dziady“ kennzeichnet besonders dies, daß mit den heidnischen Festgebräuchen christliche Vorstellungen vermengt sind; namentlich, da der Allerseelentag ungefähr in die Zeit dieser Feier fällt. Das Volk stellt sich vor, daß es mit den Speisen, Getränken und Gesängen den Fegefeuer-Seelen Erleichterung schaffe. (SL IXf.)

Unsere Ahnenfeier zeichnet sich dadurch aus, daß heidnische Riten mit christlichen Vorstellungen vermischt werden, besonders deshalb, weil der Allerseelentag in die Zeit dieses Festes fällt. Das Volk ist der Meinung, daß es mit Speisen, Getränken und Liedern den im Fegefeuer leidenden Seelen Erleichterung bringe. (WS 3)

$\mathrm{Zu}$ dem zweiten Zitat ist anzumerken, dass das Vorwort des Verfassers nur in der Übertragung Schamschulas so wie im Original fungiert, d.h. als einführender, an einer exponierten Stelle untergebrachter Sachtext. Lipiner baut das Vorwort in seine eigene Einleitung ein, die von den meisten Lesern wahrscheinlich ohnehin übersprungen wird. ${ }^{46}$ G. Hagenau lässt den Metatext aus offensichtlichen Gründen weg.

Die beiden angeführten Stellen sind ein gutes Beispiel dafür, wie unvergleichlich leichter sich religiöse Vorstellungen in der Übersetzung rein lexikalisch wiedergeben lassen, wenn sie im Original explizit genannt werden (hier als die katholische Lehre vom Fegefeuer). Sobald aber das dogmatisch determinierte Weltbild von Dziady durch bestimmte Motivketten, Metaphern und andere poetische Mittel impliziert bzw. gar auf der Ebene der Grammatik realisiert wird, unterliegt es in den Zieltexten weitgehenden Transformationen.

${ }^{46}$ Der zwischen der Ballade Upiór und dem Teil II stehende Rückverweis des Übersetzers ist auf Grund seiner graphischen Gestaltung kaum zu bemerken. Die anderen Metatexte in Dziady behält Lipiner allerdings bei. 
In keiner der Übersetzungen ist Gustav als Angehöriger der Lebendigen und der Toten zugleich erkennbar, das seinem Wesen immanente, ausgewogene Verhältnis zwischen Dies- und Jenseits, die sich gegenseitig durchdringen, wird gestört: bei Lipiner - zugunsten des Überirdischen (der Held als Toter); bei Schamschula zugunsten des Irdischen (Gustav als Lebendiger). G. Hagenau verflacht ihren Protagonisten zu einem Gespenst aus einer Gruselgeschichte. Die geistige Anwesenheit der Seelen der Verstorbenen in dieser Welt kommt in den Nachdichtungen nicht zum Tragen. Die eigene erinnerte Vergangenheit, der Erinnerungsprozess wird entweder ausgelassen (Hagenau) oder als „soziales“ Gedenken und Gemahnen verstanden; bemerkenswerterweise weichen aber sowohl Lipiner als auch Schamschula den „,kulturmarkierten“ Lexemen gerade dort aus, wo sie durchaus am Platz wären: dziady - święto pamiatek wird konsequent als Erinn'rungsfeier (Lipiner) bzw. Erinn'rungsfest (Schamschula) übertragen. Die Rolle des mehrdeutigen Erinnerungsmotivs bei der sprachlichen Mitgestaltung des Weltbildes von Dziady wird von den Autoren der Zieltexte weitgehend übersehen.

Ein auffallendes Merkmal der Nachdichtung Schamschulas ist das häufige Einbauen religiöser Metaphern und Anspielungen, die aber zum religiösen Weltbild des Originals nichts beitragen - im Gegenteil: Der Protagonist wird gewissermaßen gläubiger (im Sinne pietistischer Frömmigkeit) und weniger „heidnisch“ als bei Mickiewicz.

Eine genau entgegengesetzte Tendenz ist dem Bühnentext von G. Hagenau anzumerken, der insgesamt weniger religionsbetont ist als die polnische Vorlage und die beiden anderen Nachdichtungen. Die "Seelen der Mitchristen“ im Fegefeuer (spótchrześcijan dusze - AM 39), für die der Priester in Teil IV am Allerheiligentag betet, werden bei Hagenau gar zu halbchristlichen Seelen (GH 194).

Dass die Übersetzerin das Ritual der Ahnenfeier eher als folkloristisches, etwas naives Beiwerk der Dichtung denn als Zeugnis tiefster katholischer Gläubigkeit versteht, darf nicht verwundern im Kontext ihrer Einleitung, in der wir lesen: „Doch meine ich, daß gerade in unserer Zeit dies von Geistern und paranormalen Erscheinungen wimmelnde Meisterwerk des polnischen Romantikers Mickiewicz interessant sein könnte, wo doch besonders unter der Jugend die Esoterik[L1] und Parapsychologie so hoch im Kurse steht und die diversen Gurus sich regen Zuspruches erfreuen. ${ }^{47}$ Es stellt sich nun die Frage, ob die Übersetzerin, die den katholischen Glauben durch Esoterik und Parapsychologie ersetzen möchte, um Dziady dem Erwartungshorizont der potentiellen Zielleser bzw. Zuschauer anzupassen, das Weltbild des dramatischen Fragments nicht etwa verfälscht.

Anhand der hier durchgeführten Analyse könnte man die These aufstellen, dass das katholische Weltbild eines der wesentlichen Hindernisse im Prozess der Rezeption und der übersetzerischen Erschließung von Dziady im deutschspra-

${ }^{47}$ G.Hagenau: Adam Mickiewicz als Dramatiker. Dichtung und Bühnengeschichte. DziadyTotenfeier. Deutche Übersetzung, op.cit., S.7_f. 
chigen Raum war und ist. Die religionsbedingten Elemente des Weltbildes werden in den Übersetzungen unabhängig von der Epoche verkannt bzw. verändert. Da diese Tendenz sowohl in der Fassung Lipiners als auch in der Nachdichtung Schamschulas - zwischen denen immerhin ein ganzes Jahrhundert liegt - erkennbar ist, kann man vermuten, dass es sich um ein objektives und überzeitliches Hindernis handelt. Das dramatische Fragment Dziady ist das einzige Werk Mickiewiczs, in dem das religiöse Element derart dominiert (in der „Konrad-Dichtung“ kommt noch der Marienkult als ausgesprochen katholisches Merkmal hinzu), und es dürfte kein Zufall sein, dass gerade dieser Text so lange ohne eine vollständige deutsche Übersetzung blieb. Die im Drama präsente traditionelle katholische Religiosität als Rezeptionsblockade erwähnt am Rande auch Brigitte Schultze, die jedoch die Aufnahme von Dziady im deutschen Sprachraum vorwiegend aus der Perspektive der unterschiedlichen Theatertraditionen in Polen und in den deutschsprachigen Ländern betrachtet. ${ }^{48}$ Es ist aber vielleicht nicht ohne Bedeutung, dass zwei von den drei Übersetzern der Dziady, nämlich Siegfried Lipiner und Gerda Hagenau, ihren Lebensmittelpunkt im katholischen Wien hatten.

Wie lebendig der Glaube an die Gemeinschaft der Heiligen in Polen noch immer ist, erkennt man am besten auf polnischen Friedhöfen, die - im Unterschied zu den Friedhöfen in Westeuropa - am 1. November einem Lichtermeer ähneln. Mit der Ausbreitung des Laizismus in Europa wächst die Bedeutung religionsbedingter Rezeptionsblockaden - insbesondere dort, wo es gilt, einen Text wie Dziady mit seinem katholischen Weltbild in den Kulturkanon des protestantischen Bürgertums zu verpflanzen. ${ }^{49}$ Somit verliert das Hauptwerk Mickiewiczs immer mehr seine Chancen, sich beim deutschsprachigen Lesepublikum als ein Werk der Weltliteratur zu etablieren.

${ }^{48}$ Vgl. Brigitte Schultze: Rezeptionsblockaden des deutschsprachigen Theaters für Mickiewicz, Krasinski, Stowacki und Wyspiański. In: Polnisch-deutsche Theaterbeziehungen seit dem Zweiten Weltkrieg. Hg. von Hans-Peter Bayerdörfer in Verbindung mit Małgorzata Leyko und Małgorzata Sugiera. Tübingen 1998. S. 153 sowie dies.: Das kanonische Bühnenwerk bleibt Lektüre. Mickiewiczs Dziady (Ahnenfeier) im polnisch-deutschen Kulturtransfer. In: Komödie und Tragödie - übersetzt und bearbeitet. Hg. von Ulrike Jekutsch, Fritz Paul, Brigitte Schultze und Horst Turk. Tübingen 1994. S. 399.

49 Zur übersetzungsrelevanten Bedeutung verschiedener Kulturkanons vgl. Maria Krysztofiak: Przekład literacki a translatologia. Wydanie drugie, poszerzone i poprawione. Poznań 1999. S. 82 ff. 